Thyroid Treatment.

In Beatson's, Cheyne's, and Herman's cases thyroid extract was given while the effects of the oöphorectomy were being observed. Regarding it as a powerful "lymphatic stimulant," Beatson put his cases on thyroid for a month or so and seemed to obtain no result. He then tried oöphorectomy plus thyroid and obtained more or less result, which, I should say, oöphorectomy alone will explain. In short, I thought that Beatson's cases went to show that thyroid was of no use in scirrhus of the breast. It is, however, right to say that Dr. Beatson came to an opposite conclusion. The remarkable case of Recurrent Carcinoma of the Breast entirely disappearing under Thyroid Extract continued for Eighteen Months, published by Page and Bishop, made me feel that perhaps thyroid acted very slowly, and that its effects could not be seen during a month's exhibition. It may be so; but careful reading of the case does not support this view strongly. The patient was aged 6r. After thyroid had been administered some time, the nodules ceased to grow and seemed softer; but later a fresh one appeared and grew, and none seem to have disappeared during fourteen or fifteen months. Then the patient disappeared, but continued taking the drug. At the end of eighteen months she turned up again, all the nodules having gone in the interval-I should imagine very much to the astonishment of both doctor and patient, who must have been quite unprepared for such a development. The result does not read like that of the steadily-continued or increasing action of a drug.

The' following are the results of treatment with thyroid in my cases:

In Case II, when nodules began to reappear after the oöphorectomy the patient having gained fesh up to the commencement of the thyroid diem being reached. The patient lost 5 lbs.

In Case vil the administration of thyroid was begun in June, and was continued with great pertinacity almost to death in september. Full inhibition of growth of the fungating masses were results of the treat ment.

Mrs. K., 5o, had a rather large and quick-growing cancer, infiltrating breast and involving skin diffusely; freely removed in November, 1897 . In June, 1898 , she returned with several nodules in skin and fat in and around scar and a diffuse redness, with slight infiltration spreading far towards axilla; general condition still good. She was given thyroid gr. $x$ to gr. Xv a day. No improvement was noted, but slow increase went no post-mortem examination.

Mrs. B., 52, whose mother died of cancer of breast, had a large quicklygrowing cancer of breast, involving skin, freely removed in November. I897 In May, 1898 , she had recurrence in middle of scar and extending far out into axilla. I put her on $7 \frac{1}{2}$ gr. of thyroid a day, and after a fortdepressed that she had to give up for a week; then she started ro gr. a day, and after three weeks of this-that is, seven weeks from beginning of treatment-she and her nurse agreed that the disease had not increased lately, and the patient maintained that the mass was softer. At a later period, after a three weeks' interval, both the patient and her medical thrroid produced softening, were convinced that the re-exhibition With this exception no effect of the thyroid on the growth was noted. From ro to 15 gr. of the drug were taken daily with few intervals; it seemed to oause great depression and vomiting, but these may have been due to the disease. The patient is now (Deeember 2qth, r898) bedridden, with a good deal of local disease ulcerating centrally; a huge liver, witl jaundice and ascites, and a large mass in right iliac tossa

Mrs. N., 63, very stout, had a large tumour of breast, with a deepish ulcer, discharging freely, running into it; many nodules in skin over breast, one large and almost bursting; enlarged axillary glands. She took 3 to 6 gr. Of thyroid daily irregularly; after two months the ulcer completely healed, and now, after four months, there has been little or no local increase. The large nodule remains in statu quo. There is reason o fear that she has growths in the liver.

These are all the cases of cancer in which I have tried thyroid. They afford little evidence that it has any action upon the disease.

\section{ON FIBROMYOMATA OF THE VAGINA.}

By JOHN PHILLIPS, M.A., M.D.Cantab., F.R.C.P., Obstetric Physician, King's College Hospital ; Senior Physician, British Lying-in Hospital; Examiner in Midwifery, the Royal
College of Physicians.

HAVING met with two cases of this rare and somewhat important condition, I have reported them in full; and having searched the literature on the subject, have been able to add 27 additional cases published since 1882 , when Kleinwhohter wrote his standard dissertation, Die bindegewebigen und myomatösen Neubildungen der Vagina. ${ }^{3}$
CASE I (No. XXvirI in Bibliography).-Mrs. B., aged 36, with no children, was first seen in 1890 for pain during coition and reflex mammary and gastric irritation. On vaginal examination a small tumour was felt in ternum. The pelvic condition was otherwise normal. The swelling was sessile, smooth, painless, and covered by healthy mucous membrane, which could be freely moved over its surface. In size the tumour appeared to be that of a shelled walnut. $A$ diagnosis of vaginal cyst was given, and under an anæsthetic an incision was made, and the nature of by swelling discovered; watures, and the vagina stuffed with gauze. by deep and superficial sutures, and the vagina stuffed with gauze. was found to be partly myomatous and partly fibrous the latter predominating For some reason, all the local and reflex symptoms above; mennating. For some reason, all the local and

CASE II (No. XXIX in Bibliography).-Miss A., aged 49 , had been a martyr to neuralgia and rheumatism all her sexual life, and had been more or less continuously under medical care. Three years before I first saw her (F.ebruary 5 th, 1898) she complained to Dr. Ferris, her medical attendant,

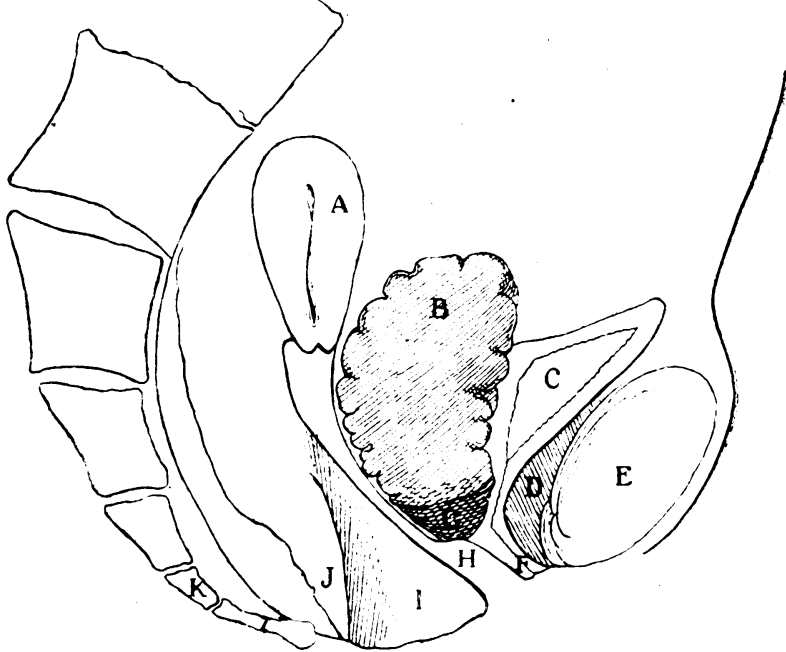

Fig. r.-Case II ; $\Lambda$, uterus (retroverted) ; B, tumour; C, blaclder ; D.

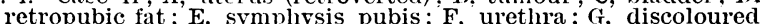
retropubic fat ; E, symphysis pubis; F. urethra; $\mathrm{G}$, discoloured
portion of tumour ; H, vagina; I, perineum ; J, rectum; K,

of something pressing upon her bladder. An examination showed a small, apparently fluctuating, swelling in the anterior and lower vaginal wall. This growth had slowly but continuously increased in size irom that timc. Up to three or four years ago her catamenia were regular and normal, but since then she has been very irregular, long periods of amenorrhoa alternating with a few days loss. A few weeks (three or four) ago she noticed an extremely offensive discharge coming from the vagina, and it was only after much vaginal douching that the smell was overcome; this has reappeared from time to time. It was thought that perhaps the growth had ruptured and some of its contents found exit per vaginam. The patient had steadily declined operative treatment. She complains at present of the constant desire to micturate and the offensive discharge. She has made flesh, and has nothing generally wrong except beyond the sensation of a swelling in the median line rising just above the brim of the pelvis.

Per Vaginam. - The anterior half of the pelvis was occupied by an elastic almost fluctuating, smooth growth extending from just above the interna urethral orifice to high up towards the pelvic brim; it was beneath the mucous membrane of the anterior vaginal wall. It encroached upon the vaginal canal so much, that it was only after much patience and difficulty that the index finger could be pushed up sufficiently high to reach the cervix uteri. With the sound in the bladder and finger in the vagina the growth could be limited to the pelvis and the anterior vaginal wall. The mucous membrane covering it was movable over the tumour. Apparently no connection existed with the uterus. The tissues covering the lower por tion of the swelling were purple in colour. No opening could be detected in the walls of the capsule. An anæsthetic was given and the abovementioned physical signs corroborated. The uterus, of normal size, was found lying just beneath the sacral promontory slightly retroverted and impaoted. The tumour gave to the touch the sensation of a tense cys containing fluid from which a small amount had been withdrawn, leaving the walls slightly flaccid. The offensive discharge was apparently due to menstrual fluid retained in the vagina above the tumour and not to escape of cyst contents, as was at first thought possible.

Diagnosis was extremely difficult, and appeared to rest between an impacted pediculated fibroid (subserous), a rare form of anterior peri metritis, a vaginal cyst, a dermoid ovarian cyst, or, lastly, a vaginal fibromyoma. It was decided to attempt removal by the vaginal route.

Operation. - After antiseptic douching and the usual preparation, the patient was placed in the exaggerated lithotomy position and the vaginal mucous membrane over the lower portion of the growth incised longitudinally. No fluid escaped, and the tumour was obviously solid and encapsuled. It was shelled out with much difficulty and free bleeding. A sound passed 6 inches into the cavity in an upward direction after its
removal, the blunt end being easily felt per hypogastrium. Several forceps 
were left attached to the bleeding points, the cavity was swabbed out with iodine liniment and then stuffed with gauze. Recurrent liæmorrhage occurred before the patient recovered consciousness, necessitating application of more forceps. She made an easy and afebrile recovery, but neurotic symptoms have remained unaltered.

Pathological Report (by Mr. G. Lenthal Cheatle).-A tough, encapsuled, and lobulated tumour, weighing $\mathbf{1 4}^{\frac{1}{2}} \mathrm{Oz} .5$ inches in length and $3^{\frac{1}{2}}$ inches in breadth in its upper portion; its surface smooth, its shape triangular, the outline somewhat resembling a map of Great Britain. In two or three localities one marginal lobe was folded back upon the surface of the growth, and there had become attached by loose and delicate connective tissue, suggesting that possibly at the time of its removal the neoplasm was developing in a confined space. The tumour gives an indistinct sense of fluctuation to the touch.

Microscopical Examination shows that the cells in shape and arrangement very closely resemble those observed in uterine fibloids-ia mixture of fibrous and muscular elements.

As the result of a very thorough search through the literature of the subject Kleinwächter collected 53 cases; he includes, quotes, and criticises in his list Neugebauer's 35 collected cases ${ }^{2}$ and Briesky's 37 cases $^{3}$; hence with the 29 cases of which I have collected details, there are $8 \mathrm{I}$ which may be fairly considered. The first recorded instance of this condition appears to have bee $n$ in 1773 (Jakob Denys), and some of Kleinwächter's cases must be looked upon with suspicion even after his very thorough scrutiny ; his paper so thoroughly exhausts the matter at his disposal up to 1882 , that I propose only here to critically examine the 29 cases I have been able to collect.

The view held by $\mathrm{Kiwisch}^{4}$ that most of the vaginal fibromyomata originally arise from the uterus, and subsequently lose their connection with that organ, is denied by Kleinwächter, and in none of my cases has there been any apparent connection. In one only (Hastenpflug, Case xIX) was there a uterine fibroid also present. These tumours seem to occur as fibromata myomata, or a mixture of the two. The most common certainly appear to be fibromyomata ( 19 cases)

Age.-This is mentioned 24 times, the youngest patient being 29, the eldest 52, 2 being above 50, 8 above 45, and 6 above 40. These figures support Kleinwächter's opinion that fibromyomata of the vagina are met with chiefly in the later sexual period and at the menopause. At the same time 3 fairly authenticated cases by Traetzl, ${ }^{5}$ Wilson, ${ }^{6}$ and Martin occurred in infants aged respectively $1 \frac{1}{4}$ and $2 \frac{1}{2}$ years, and in a newly born girl.

Size varies very much ; the largest is mentioned by Gremler, which weighed Iolbs. $2 \frac{1}{2}$ ozs., the tumour hanging like a large flask from the vagina by a pedicle two fingers thick. In two instances the tumour was of the size of a child's head (Cases XII and XV), and every size from a large apple to a lentil has been noticed, the most common being that of a shelled walnut.

Seat.-These growths are always single, and may be pediculated or sessile; in all probability they are invariably the latter during the earlier part of their life-history. The anterior vaginal wall is most commonly affected, and in any part from the urethral orifice to the fornix. Out of 39 of Kleinwächter's cases in which the seat is mentioned, it was 25 times on the anterior wall; and of my 29 cases, 23 times, and either to the right or to the left of the median line.

Degenerations.-Gangrene of the vaginal mucous membrane covering the tumour occurred in five instances (I, XII, XVIII, XXVI, XXIX), and two interesting changes in the tumour itself have been recorded, namely, calcification and formation of hæmatoma, in the substance of the growth. In the former (Strassmann's case, XIII) the patient had a year and a-half before swallowed a pin, and for some months had had stabbing pain between the vagina and anus, wnich she attributed to the point of the pin. On examination, immediately beneath the mucous membrane of the vagina a lobulated hard body the size of a lentil, was felt; on enucleating it, it was found to be a fibroid undergoing calcification and in no way connected with the pin. In Hofmokl's case (xV) the tumour was aspirated, and pure blood withdrawn, and on removal of the tumour there was found a roundish cavity with rough walls of fibromyomatous tissue; he considered this an instance of a true hæmatoma.

Symptoms must necessarily depend upon the size, situation, and rapidity of growth of the tumour; any pathological changes, such as calcification and sloughing, must also be borne in mind. The rate of growth is variable-as a rule very slow. In Case III it occupied ro years in attaining to the size of a hen's egg, while in Case xxy it had grown very slowly for 4 years, then suddenly increased in 6 months to twice its size. In the second of $m y$ cases the tumour had been known to exist for at least 3 years. In 5 cases the tumour gave rise to no symptoms whatever, and in 2 others the patient applied for relief because she felt a "lump." Other symptoms noted were difficulty in micturition ( 5 times), dyspareunia (4 times), rectal obstruction (3 times), backache, dragging pain, difficulty of locomotion and reflex disturbances are also mentioned. The effect on menstruation is slight In those cases in which metrorrhagia was complained of it might well have been due to irregular bleedings from the ulcerated tumour surface. In the 29 cases this effect was recorded 24 times, and in only 5 was there menorrhagia Kleinwächter is inclined to the opinion that there is a tendency to amenorrhoea in these cases. The liability to conception appears to be unaltered, and pregnancy has no apparent effect on the growth of these tumours. similar to that observed in uterine fibromyomata. During labour the growth may obstruct labour and the puerperium may be complicated by sloughing of the tumour itself ${ }^{9}$ or of the vaginal wall, producing a vesico-vaginal fistula (Case I).

Differential diagnosis must be made from vaginal cyst, pediculated subserous uterine fibroid, primary malignant disease. The first of these is frequently a source of error, tapping being productive of a negative result. In my second case (XXIX) fluctuation certainly appeared to be present, and after removal the tumour gave a peculiar sensation as of fluid in a cavity with lax walls.

Treatment.-Should the growth be small and observation show it to be quiescent, no operative interference is necessary. When, however, steady increase in size, or pediculation, or sloughing is noted, surgical treatment is absolutely necessary. Many methods have been resorted to, among them torsion of the tumour, ligature of its pedicle, galvano-cautery enucleation and suture, and the écraseur. An ideal treatment seems to be incision and enucleation with deep and superficial suturing in sessile growths, and ligature of the pedicle in portions, and removal in polypoid cases. strict asepsis is obviously necessary. Of the 29 cases mentioned in 21 incision, enucleation, and gauze packing was resorted to with the best results. In a polypoid tumour weighing $1 \frac{1}{2} \mathrm{lb}$, and entirely filling the vagina, Storer (Case xxIII), after attempting to cut through the pedicle with a wire écraseur, succeeded with a chain, and found that all attempts to remove the free growth from the vagina were ineffectual ; he therefore "passed the forearm into the rectum after forcibly dilating the sphineter, and by downward pressure from above delivered the tumour." In Case Xviri the tumour was delivered by the obstetric forceps, and by the finger in the rectum; the pedicle was then ligatured in pieces, and the tumour removed; it was in a state of sphacelus, and was $16 \frac{1}{2} \mathrm{~cm}$. in length. I have not met with any case in which abdominal section was found to be necessary. Torsion is dangerous, as it is quite easy in tumours situated in the anterior wall to draw the bladder into the pedicle, and so produce a vesico-vaginal fistula. A word of warning should be given when the tumour is enucleated; the parts are very vascular, and often recurrent hæmorrhage takes place, as in my second case.

Conclusions.-Vaginal fibromyomata are invariably single and usually slow growing; their situation is most frequently upon the anterior vaginal wall, and they may be sessile or pediculated. They have practically no effect upon menstruation, conception, or the course of pregnancy, but may lead to serious dystocia. Symptoms depend upon size and situation, and are usually due to direct pressure exerted on neighbouring viscera. Sloughing is the most common change in the tumour during the life-history. Removal is best carried out by enucleation and suture, or stuffing the sac. with gauze.

1 Zeit. f. Heilk., Bd. iii, p. 335. 2 Prager Vierteljahrschrift, $\mathbf{1 8 7 7}$, Bd. ii, p. 59. 3 Biliroth's Handbuch der Frauenkrankheiten, Bd. iii, p. 723. 4 Klin. Corträge, Bd. ii, p. $545 .{ }^{5}$ Allgem. Wien. med. Zeit., I868, Bd. Xx, p. 227. 406. ${ }^{8}$ Neugebauer, p. 79. 9 Porro's Case, Ann. de Gynéc., 1876, p. 72

BIBLIOGRAPHY OF THE TWENTY-NINE CASES.

CASE I. Macan, Dublin Quarterly Journ. Med. Sc., r881, vol. Ixxi, p. 156. (II) Donald, Medical Chronicle, vol. ix (x888-9), p. 303. (III) C. M. Green, A 
exxvii, p. 594. (IV) Da Costa, Large Fibroid Tumour of the Anterior Wall of the Vagina, Medical News (Philadelphia), 1895, vol. lxvii, p. 463. (v) Cas well, Fibroma of the Vagina, Boston Med. and Surg. Journ., r88, cix, p. I5x. (VI, VII) Gaye, Berl. klin. Woch., 1882, No. 43, p. 652. (VIII) G. Braun, Gebrauch enes bei Extirpation eines Fibroms der vorderen Vaginalwand
benützen Spekulums, Wien. med. Woch., 885 , xxxv, pp. 1557-9. (IX) Lewers, Obstct. Trans. (London), 1887, vol. xxix, p. 299. (x) Tillaux, Fibro-myome de l'Urethre, Annales de Gynecologie, r889, vol. xxxii, p. 166r. (XI) Herman, Obstet. Trans. (London), 188o, vol. xxii, p. 44. (XII) Stumpf, Myofibrom der Vagina mit beginnender Verjaucluung, Miinch. med. Woch., r89o, xxxvii, p 694. (XIIr, XIV) P. Strassmann, Zur Kenntnis der Neubildungen dee Scheide, Centralbl. f. Gymäk, r89, p. 825. (xV) Hofmokl, Entfernung eines Kindskopfgrossen Fibromyom der vorderen Vaginalwand durch elastische Ligatur, Wien. med. Presse, r891, xxxii, p. r229. Hasenbalg, Fibröser Polyp der Vagina, Zeits. f. Geb. u. Gynäk., 1892, xxiii. p. 52. (XvII) A. Breisky, Handbuch der Frauenkrank, , Bd. iii, p. 73r. (XVIII, XIX, XX) Hastenpflug,
Ueber Vaginal-Myome, Inaugural Diss. Jena, 1888. (XX1) C. Cleveland, Ueber Vaginal-Myome, Inaugural Diss. Jena, 1888. (XX1) C. Cleveland,
Aew York Journal of Gyn. and Obstet., r893. vol. iii, p. r54. (XxII) Wernitz, Centralbl. f. Gynäk.. 1894, No. 26, p. 632. (XXIII) Thoornton Parker, Virginia Medical Monthly, Richmond, 1886-7, xiii, p. 793. (xxIv) Alfred C. Godfrey, Fibro-myomata of the Vaginal Wall, Colorado Medical Journal, x896, No. 9 ,
p. 284. (xxv) J. C. Moore, St. Louis Med. and Surg. Journal, 1385 , vol. xlviii, p. 284. (XXV) J. C. Moore, St. Louis Med. and Surg. Journal, 1385, vol. xlviii, préthral du Vagin, Archives Provinciales de Chirurgie, Paris, I894. (xxvII) Paquet, Tumeur Fibreuse du Vagin, Bulletin Médical du Nord, 1882, No. 2, p. 65. (XXVIII, xXIX) John Phillips, present article.

\section{AFTER-EFFECTS OF ABDOMINAL SECTION.}

By MAY THORNE, L.S.A., M.D.Brux.

Assistant Anæsthetist (late Senior House Surgeon), New Hospital for Women.

Ar the meeting of the Obstetrical Society held in October, 1897, Dr. Herbert Spencer pointed out that intestinal obstruction from the adhesion of the intestine to the stump after ovariotomy was by no means rare, and a month later at the Harveian Society Mr. Doran drew attention to the fact that hernia of the abdominal cicatrix frequently followed laparotomies.

These two important statements are of such interest to all practitioners that it has been my endeavour to gather together as accurately as possible statistics of these complications in women patients from the records of general hospitals throughout the country. Thanks to the great courtesy of members of the staff and of the surgical registrars of 49 hospitals, the following information has been obtained. Several country hospitals were invited to send statistics, as it seemed probable that cases of acute intestinal obstruction would be treated in them, even though the primary operation had been done in a hospital in some large centre, as London, Edinburgh, or
Dublin.

During the last four years 39 cases of ventral hernia and 12 cases of acute intestinal obstruction have been traced.

The cases of ventral hernia do not include any that may have been seen in the out-patient departments, but only those that came into the wards for treatment. The date of the occurrence of a ventral hernia or of acute intestinal obstruction after the original operation is of interest as showing approximately the length of time that the giving way of scar tissue or the formation of fibrous bands may take. It has not been possible to get all the data, but in 26 out of the 39 cases of ventral hernia they are as follows: 2 cases occurred 44 years after the original laparotomy

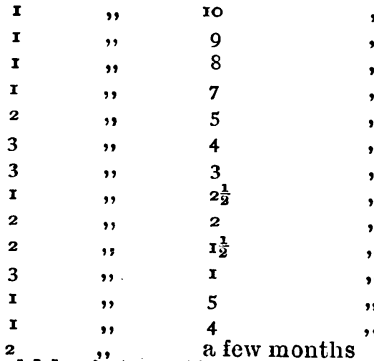

", ", ",

It would be interesting to learn in what manner the abdominal wound had been closed in these cases, whether in one or more layers, the number of cases in which a drainage tube was used, the length of rest in bed, and the use of an abdominal belt for months or years following the operation. Eighteen of the cases occurred, it will be noted, under five years, and seven in one year or under.
The dates of the cases of intestinal obstruction were as follows :

I case occurred ${ }_{4}$ years after the original laparotomy

$$
\begin{array}{lll}
5 & , & , \\
4 & , & , \\
6 \text { months } & , & , \\
2 & , \\
\text { I5 days } & , & , \\
\text { II } & , & ,
\end{array}
$$

The two cases which occurred two months after abdominal section were $(a)$ a case of perforated ulcer of the intestine, and (b) a case of sarcoma of the ovary. In neither case, therefore, was the peritoneal cavity in as sound a state as is found in the majority of cases of abdominal section, and one cannot but question whether sepsis was not responsible for the cases oocurring within fifteen days of the operation.

Dr. John Phillips gives an account of 3 cases of acute intestinal obstruction after abdominal section, the obstruction occurring one, four, and seven years after the original operation. ${ }^{2}$

I am greatly indebted to Mrs. Scharlieb, M.D., M.S., and to Mrs. Stanley Boyd, M.D., for permission to look through the casebooks at the New Hospital for Women, in order that I might trace the after-histories of patients who had had abdominal section performed there.

Information has been received of 88 patients, and, amongst these, 3 have returned for further treatment-I for acute intestinal obstruction and 2 for ventral hernia.

The history of these 3 cases is as follows:

Mrs. T., aged 22, was operated upon in 1892, when a mass was removed which consisted of the right ovary, considerably enlarged, and containing several abscess cavities and an irregularly distended long sac, which ap peared to be the Fallopian tube. The patient was very ill, with high covered, and left the hospital on the fifty-fifth day after the operation. From that time to January, 8807 , her health was good. On January 12 th, 1897 . slem complained of pain in the abdomen; on the ${ }_{15}$ th she took to her bed at home, when sickness began and was frequent. No motion or fiatus passed after the r 8 th Her medical man advised her going into a hospital, and on January 2rst she was brought to the New Hospital for Women with all the symptoms of acute intestinal obstruction. She was almost moribund on admission, and died two hours later, no operation being performed. At the post-mortem examination the intestines were found much distended and reddened, there were recent adhesions between the parietal and visceral layers of peritoneum, and also between the coils of large and small intestine centre of the transrerse colon to the back of the causing a bend and slight intestine about 13 feet from the duodenum hung down into the of sisall was constricted by a narrow white fibrous band The band passed round the loop of intestine and was continuous at one band passed round entery and at the other with the perito at one end with the mesbeyond the part involved by the peritoneal coat of intestine just was found adherent to the abdominal wall in the neighbourheod ileum iliac fossa and the stump of the right broad ligame neighourhood of the same spot. The estump of the right broad ligament was fixed at the were adhesions cæcum was bound down by dense pale adhesions. There were fixed by adhesions to the pelvic wall in the neighbourhood of the iliac vessels.

The adhesions in this case were dense and numerous. The question arises as to what adhesions were formed before the operation in 1892 was undertaken. The tumour removed contained abscess cavities, and one might reasonably suppose that inflammatory conditions were present in the neighbourhood of the right ovary, which was removed. The patient's convalescence was long, and gave rise to much anxiety, and possibly it may have been during this time that adhesions were formed, which subsequently became dense and fibrous.

The two cases of ventral hernia are as follows:

Mrs. L., laundress, aged 45, very stout, was operated on for double ovariotomy in $x 888$; 'she made a good recovery, and kept in excellent
health, and did her work till 1894 , when she first noticed a swelling in the middle of the scar about the size of a walnut This increased in size, the she suffered from griping pain till she returned to the hospital in 1895 , when she was readmitted. At the operation it was found that the omentum was extensively adherent to the parietal peritoneum under the scar. The patient made an excellent recovery.

A. D., a dwarf with contracted pelvis, aged 30 , had Cæsarean section performed at full term in 1895 . She recovered well. She was readmitted in 1896. suffering from profuse losses, when an abdominal hysterectomy was performed. In 1897 she returned with a ventral hernia in the middle of the scar, which she was anxious should be dealt with. At the operation several coils of intestine were found adherent to the parietal peritoneum

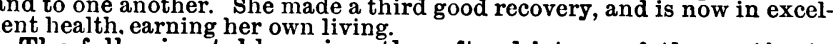

The following tables give the after-history of the patients who have been traced:

$$
\text { 2 Lancet, Novem'er 27th, r897. } 2 \text { Lancet, } 1892 .
$$

